\title{
INFORMATION AND TRANSIT SPACES AS THE MAIN CHALLENGES OF THE MODERN WORLD
}

\author{
Tatiana Martsinkovskaya ${ }^{1}$, \& Svetlana Preobrazhenskaya ${ }^{2}$ \\ ${ }^{1}$ Institute of psychology, Russian State university for the humanities, 125993, Miusskaya square 6 , \\ Moscow, Russia; Psychological Institute RAE, 125009 Mochovaya 9, Moscow (Russia) \\ ${ }^{2}$ Russian State university for the humanities, 125993, Miusskaya square 6, Moscow (Russia)
}

\begin{abstract}
Space and time in the modern world are changing rapidly. These changes affect people's lives in several temporal and spatial dimensions. In recent decades, a new sphere has emerged, the sphere of virtuality, which a person constructs himself and for himself. We can say that for modernity - both real and virtual, the continuity of the process of changes that occur simultaneously in the network and in reality, and always with an uncertain outcome is typical. Phenomenologically, one can speak about many similar features uniting real and virtual spaces. The objective space and the life time of people in the transitive world are connected with the subjective construct of space and time that a person constructs in the virtual world. We can also assume the similarity of different types of transitivity (crisis and fluid) with different types of work in virtuality (on-line and off-line). Therefore, it is important to understand the styles of behavior, the emotions of people in a situation of different changes, different types of transitivity and different types of Internet communication.

These questions became the base of the empirical study which was carried out in 2018-2019 years and consisted of two stages. The study involved young people $(\mathrm{N}=140$, age 18-21), students of Moscow universities. They were asked to answer questions of the K. Riff method "Scale of psychological well-being" in different versions - on-line and off-line. After that, they were offered two series of stimuli - words related to positive and negative events occurring in the real and virtual world with the fixation of RAG. The obtained results showed that in general in the on-line situation the overall level of psychological well-being is lower than in an off-line situation. It is disturbingly, that self-acceptance is higher off the net. That is, the constant "transparency" of communication and the openness of one's life to others, possibly stimulate personal development, but reduce self-esteem and self-acceptance. The incapacity to manage the environment, including positive contacts with others, the inability to quickly navigate information and the harshness of the situation negatively affect attitude to one-self, reducing self-esteem and intention to self-development, which generally reduces the subjective feeling of emotional comfort and well-being. The similarities in the profiles obtained by presenting positive and negative words showed the similarity in emotional responses to crisis situations in the real and virtual world. In this case, a steady increase in excitation from stimulus to stimulus occurs. Thus, we can say that the constant situation on-line becomes a difficult life situation for many young people. The phubbing and "transparency" of the network most negatively affects people who assess the situation as rigid transitivity.
\end{abstract}

Keywords: Virtual, transitive space, emotional well-being.

\section{Introduction}

The space and time in the modern world are rapidly changing. These changes affect people's lives in several temporal and spatial dimensions. Life passes in parallel in the social (objective) and personal (subjective) space and time. In recent decades, a new sphere has emerged, covering precisely personal space and time, the sphere of virtuality, which a person builds himself and for him-self. The appearance of a virtual parameter gives greater freedom for self-realization and, at the same time, enhances disharmony of different spheres of life. We can say that modernity, both real and virtual, is characterized by the continuity of changes that occur in parallel in the network and in reality, and always with an uncertain outcome. At the same time, many options and contexts, many possible choices feed the transitivity, which is constantly changing from fluid, to crisis and vice versa. 
Currently, the influence of transitivity is increasing significantly, affecting all areas of everyday life. The role of the information space is also growing because information sets not only the trajectory of socialization, but also patterns of behavior, identification standards for a large group of people (Barker, Bornstein, 2010; Chan Hoong, Soon, 2011). The fact that broadcast media samples are constantly changing in accordance with the variability and multiplicity of social contexts of the environment helps people, especially children and adolescents, to cope with uncertainty (DePaulo, Morris, 2005). Changing and therefore remaining relevant information enables people to preserve themselves, their individuality and integrity in the ever-changing circumstances of everyday life (Grishina, 2017; Borkenau, Mauer, 2006).

The connection between network and transitive spaces appears, first of all, in the uncertainty and multiplicity of contexts, groups, languages, and variants of identity. The uncertainty of these spaces is closely related to variability. The criteria by which people evaluate and present themselves to others are constantly changing. It's "likes" and reposts, social status or the number of citations (h-index). At the same time, the number of socialization groups is an important indicator both in a transitive real society and in a networked, virtual space.

It is possible to distinguish two interconnected phases - hard, crisis and fluid, soft transitivity. But uncertainty, multiplicity and variability remain dominants of the general direction of development of society, changing the degree of their cardinality (Martsinkovskaya, 2018, 2019; Astrid, Bernd, Machilek, 2006).

From a psychological point of view, we can say that crisis hard transitivity is a specific shock situation for people, with high demands on their vitality and emotional stability. But psychologically, fluid transitivity becomes much more severe. Changes occur, varying lives, values, communication, information streams and the technological environment of people. And the confidence is arising that these changes are inevitable and unstoppable (Osman, 2018).

In recent years, the phases of crisis and fluid transitivity coexist with each other, and, most importantly, their relationship is closely connected with the information flow. At the same time, constant inclusion in the information flow reduces uncertainty, making variability a familiar component of the world. Therefore, the new generation connects the real and network spaces into a single whole, which actualizes the problem of studying the determinations of mental development simultaneously in two spaces.

Along with different types of transitivity, we can talk about different forms of virtuality - on-line and off-line. We can also see the relationship between crisis and on-line situations. These situations are similar because in both cases it is difficult to change something and a quick reaction to the situation is needed. There is also a certain similarity between fluid transitivity and off-line in virtual space. Here you can slightly change the reaction, evaluation, standards. Therefore, these situations are reversible within certain limits.

Therefore, it is important to understand the styles of behavior, the emotions of people in a situation of different changes, different types of transitivity and different types of Internet communication.

\section{Problem}

Theoretical and empirical works show that the emergence of a new technological space, the Internet, social networks and gadgets poses several questions that are closely related to each other and with an analysis of the impact of information socialization on the mental development and emotional well-being of children, adolescents and youth. At the same time, the question arises of how on-line and off-line options for using gadgets affect the psychological well-being of young people and what factors help to overcome the psychological, emotional discomfort and tension associated with the constant positioning of young people simultaneously in network and real spaces.

\section{Design, methods, study participants}

Based on the posed questions, an empirical study was carried out. The study involved young people $(\mathrm{N}=140$, age 18-21), students of Moscow universities. At the first stage, students were asked to answer questions of the C.D. Riff "Scale of psychological well-being" in different versions - on-line and off-line (Lepeshinskiy, 2007). After that, they were offered two series of stimuli - words related to positive and negative events occurring in the real and virtual world with the fixation of RAG.

All study participants were aware of its objectives and agreed to participate in the work. 


\section{Results}

At the first stage, when students were asked to answer the C.D. Riff scale questions, the on-line option was proposed, and after three days the off-line option. Thus, re-testing was carried out in an obviously more favorable variant for the participants. The answers are presented in table 1.

Table 1.

\begin{tabular}{|c|c|c|c|c|c|c|}
\hline \multicolumn{2}{|c|}{ Scales } & & & \\
\hline $\begin{array}{c}\text { Positive } \\
\text { relations }\end{array}$ & $\begin{array}{c}\text { Environmental } \\
\text { management }\end{array}$ & Self-acceptance & $\begin{array}{c}\text { Personal } \\
\text { growth }\end{array}$ & Autonomy & Life goals & $\begin{array}{c}\text { of } \\
\text { psychological } \\
\text { well-being }\end{array}$ \\
\hline 67 & 64 & 58 & 64 & 52 & 68 & 373 \\
\hline 58 & 56 & 64 & 59 & 58 & 60 & 365 \\
\hline 66 & 51 & 63 & 63 & 50 & 65 & 358 \\
\hline 65 & 66 & 57 & 60 & 59 & 63 & 370 \\
\hline
\end{tabular}

The results of the correlation analysis of the components of psychological well-being by groups according to the Spearman criterion showed statistically significant differences on the scales: "Positive relations" $(p=0.042)$, "Environmental management" $(p=0.001)$, "Self-acceptance" $(p=0.016)$, "Psychological well-being "( $\mathrm{P}=0,038)$, , Life goals" $(\mathrm{p}=0,015)$.

At the second stage, the general background of the skin-galvanic reaction was measured, and then stimulus blocks of words were presented with a break of 2 seconds between words and 5 seconds between blocks. In total, five blocks of stimulus words were used: positive; neutral; negative; transitive; virtual. Blocks were formed on the basis of the most frequent assessment of the word as bearing the positive / neutral / negative meaning by the expert group of psychologists.

Processing of the obtained data was carried out using the statistical software package STATISTICA 12.0.

It can be seen a decrease in activity upon presentation of positive stimuli compared to recording the background activity. When neutral stimuli are presented, the activity is equal to the initial background. A noticeable surge in RAG activity is observed upon presentation of negative stimuli and increases significantly upon presentation of special blocks reflecting network and real transitivity. As expected, negatively charged stimuli cause a more emotionally vivid reaction than positive ones.

It can be seen that obtained data is equal both in the left and right channels (see figure 1 and 2).

Figure 1. Data from the left channel.

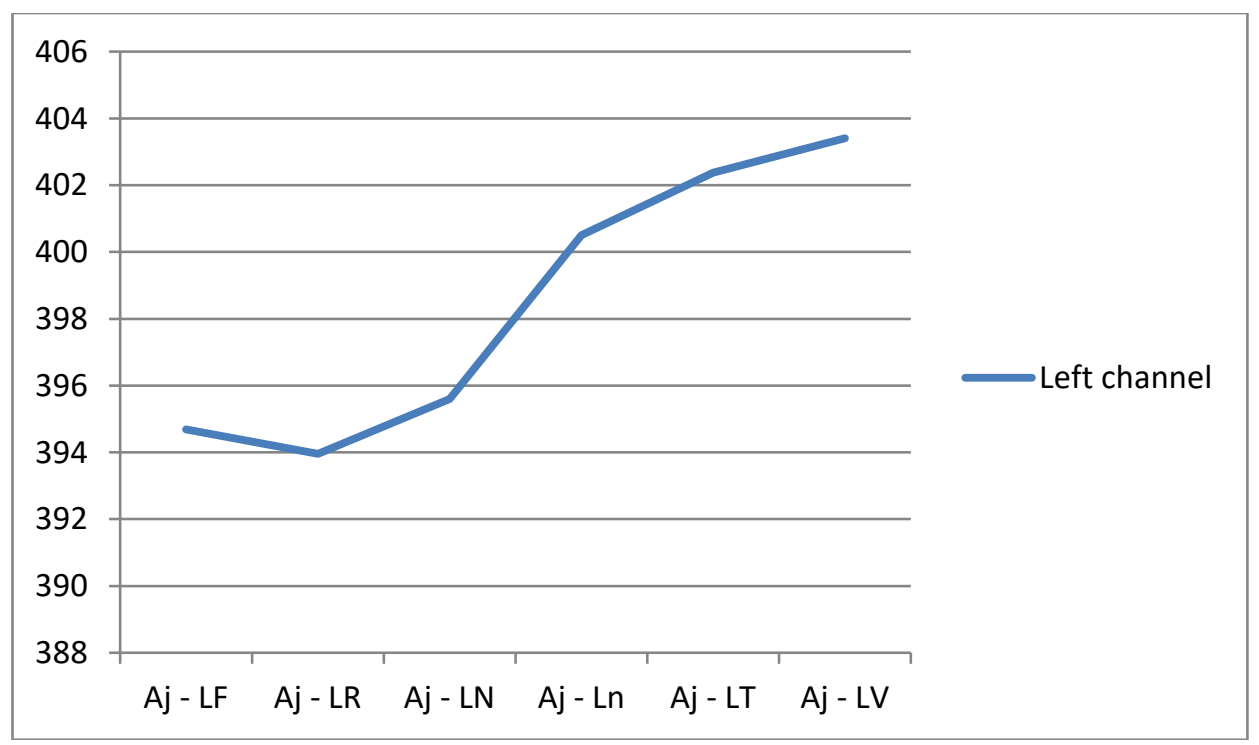


Figure 2. Data from the right channel.

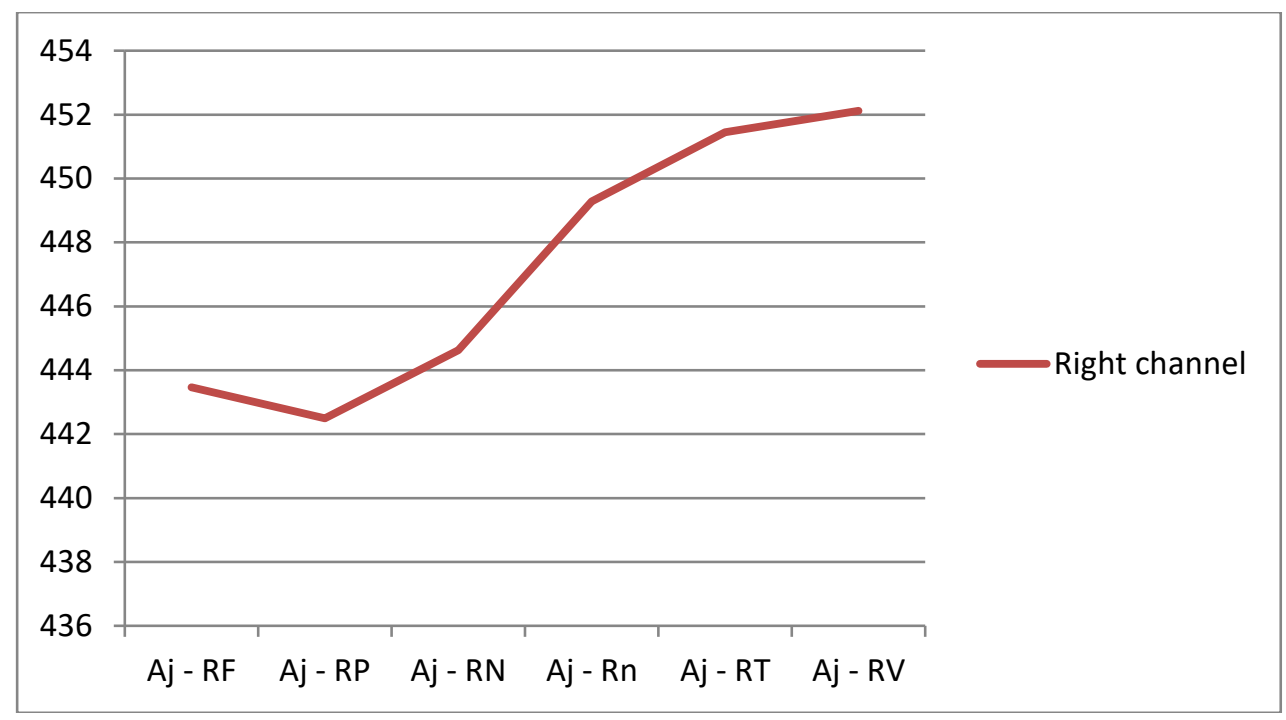

\section{Discussion}

We can see that the in on-line situation the overall level of psychological well-being is slightly higher than in the off-line situation. Of particular interest are indicators on separate scales. In the on-line situation are higher indicators: Environmental management; Personal growth; Positive relationship; Life goals. Considering that a permanent stay in the network is a common situation for most students, these data show that the online situation stimulates their desire for personal growth and self-realization, as well as to establish empathic relationships with others.

As can be predict in offline situation the level of autonomy is higher. However, it is troubling that self-acceptance is also higher outside the network. That is, the constant "transparency" of communication and the openness to others, possibly stimulates personal development, but reduces self-esteem and self-acceptance.

Based on this, we can conclude that for young people on-line is a familiar, natural environment in which they are constantly open to new experiences and can evaluate their actions with others. Therefore, such "transparency" is somewhat annoying for users. No less interesting is the analysis of differences in the responses assessing the "environmental management" parameter. If in the first variant they must manage situation quickly, since it can radically change, then in the second, on the contrary, the focus on the long-term fixation of changes that do not need to be forced becomes obvious.

Apparently, the situation of constant changes exhausts some students and leads to a decrease in the indicators Environmental Management and Life goals. Thus, we can assume that the situation of transitivity in the network and in reality, becomes a difficult life situation, reducing subjective well-being.

The data of the skin-galvanic reaction confirmed a positive reaction to the words of the network transitivity block as reflecting the daily activity of students. Young people noted that in the network space they not only chat with friends, but also find very quickly the necessary information. Words reflecting the transitivity of time-space also caused a high skin-galvanic reaction. This reaction was caused by the individual attitude of students to the words of the block, which are important for them.

\section{Conclusion}

The incapacity to manage the environment, including positive contacts with others, the inability to quickly navigate information and the harshness of the situation negatively affect attitude to one-self, reducing self-esteem and intention to self-development, which generally reduces the subjective feeling of emotional comfort and well-being.

The similarities in the profiles obtained by presenting positive and negative words showed the similarity in emotional responses to crisis situations in the real and virtual world. In this case, a steady increase in excitation from stimulus to stimulus occurs. Thus, we can say that the constant situation on-line becomes a difficult life situation for many young people.

The phubbing and "transparency" of the network most negatively affects people who assess the situation as rigid transitivity. 
The mixture of network and real situations is constant for most students. This becomes the reason for the close connection of the virtual and transitive worlds.

The problems arising from the active spread of the digital information space are associated not only with difficulties in the intergenerational transmission, but also with the fact that the constant on-line situation, phubbing and "transparency" of the network become a difficult life situation for many young people.

The prospects associated with the expansion of digital information socialization, in many respects become the flip side of the problems. Expanding the world-image, obtaining new experience leads to the development of intellectual and social activity and helps to understand the world. This fact reduces the fear of uncertainty and increase the willingness to change.

\section{Acknowledgments}

This work was supported by the Russian Science Foundation, project 19-18-00516 "Transitive and virtual spaces - commonality and differences".

\section{References}

Astrid S., Bernd M., \& Machilek, F. (2006) Personality in cyberspace: personal Web sites as media for personality expressions and impressions. Journal of Personality and Social Psychology, 90(6), 1014-1031.

Barker, E. T., \& Bornstein, M. H. (2010). Global self-esteem, appearance satisfaction, and self-reported dieting in early adolescence. The journal of early adolescence, 30(2), 205-224.

Borkenau, P., \& Mauer, N. (2006). Personality, emotionality and risk perception. Journal of Individual Differences, 27(3), 127-135.

Chan Hoong, L., \& Soon, D. A. (2011). Study of Emigration Attitudes of Young Singaporeans. Institute of Policy Studies, IPS Working Papers, (19). Retrieved from http://lkyspp.nus.edu.sg/ips/wpcontent/

DePaulo, B., Morris, W. (2005). Singles in society and science. Psychological Inquiry, 16(2), 57-83. doi: 10.1207/s15327965pli162\&3_01

Grishina, N.V. (2017) Everyday behavior: life style, everyday creativity and life design]. Psychological study. 10(56) 2.

Lepeshinskiy, N. N. (2007). Adaptation of the questionnaire "The scale of psychological well-being" C.D. Riff. Psikhologicheskiy zhurnal, 3, 24-37

Martsinkovskaya, T. D. (2018) Psychological aspects of technological society. Psikhologicheskie Issledovaniya, 11 (62),12.

Martsinkovskaya, T. D. (2019) Person in Transitive and Virtual Space: New Challenges of Modality. Psychology in Russia: State of the Art, 12(2), 165-176. DOI: 10.11621/pir.2019.0212

Osman, K. (ed.) (2018) Socialization. Rijeka, Croatia: InTechOpen. 